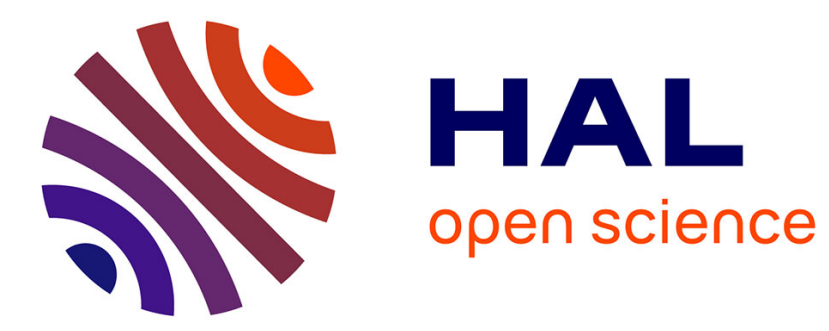

\title{
Organic electrolyte solutions: Modeling of deviations from ideality within the binding mean spherical approximation
}

Jean-Pierre Simonin, Olivier Bernard

\section{- To cite this version:}

Jean-Pierre Simonin, Olivier Bernard. Organic electrolyte solutions: Modeling of deviations from ideality within the binding mean spherical approximation. Fluid Phase Equilibria, 2018, 468 (25 July 2018), pp.58 - 69. 10.1016/j.fluid.2017.11.018 . hal-01924584

\section{HAL Id: hal-01924584 \\ https://hal.sorbonne-universite.fr/hal-01924584}

Submitted on 27 Nov 2018

HAL is a multi-disciplinary open access archive for the deposit and dissemination of scientific research documents, whether they are published or not. The documents may come from teaching and research institutions in France or abroad, or from public or private research centers.
L'archive ouverte pluridisciplinaire HAL, est destinée au dépôt et à la diffusion de documents scientifiques de niveau recherche, publiés ou non, émanant des établissements d'enseignement et de recherche français ou étrangers, des laboratoires publics ou privés. 


\title{
binding mean spherical approximation
}

\author{
Jean-Pierre Simonin ${ }^{\mathrm{a}, *}$, Olivier Bernard ${ }^{\mathrm{a}}$ \\ ${ }^{a}$ CNRS, Sorbonne Universités, UPMC Univ Paris 06, Laboratoire PHENIX, Case 51, 4 place Jussieu, F-75005 Paris, France
}

\begin{abstract}
Deviations from ideality in organic electrolyte solutions are described within the Binding Mean Spherical Approximation (BiMSA) theory, in which ions are regarded as charged hard spheres and unlike ions may associate to form an ion pair. Association is modeled within the Wertheim theory (as done in SAFT-type models). The model includes a mass action law with a thermodynamic association constant. The literature about the thermodynamic properties of this type of solution is reviewed. Besides, it is attempted to gain some insight into the solvation of ions by computing their Stokes hydrodynamic diameters from conductivity experiments, and by employing an original analysis introduced by Fawcett. The BiMSA model is used to represent the osmotic coefficient of 1-1 electrolytes in pure methanol, ethanol, 2-propanol, acetone and acetonitrile. The optimized cation sizes in the solvents are compared with their hydrodynamic diameters. The regressed association constants are compared with literature values derived from conductivity and vapor pressure experiments.
\end{abstract}

Keywords: Electrolytes, Organic solutions, Thermodynamics, Binding Mean Spherical Approximation (BiMSA), MSA.

\section{Introduction}

Mixed solvent (aqueous-organic) electrolytes have been used for some time now in many industrial processes, for example in order to optimize crystallization [1] and other separation processes in the chemical and pharmaceutical industries, such as water-alcohol distillation [2]. In probably more recent times, solutions of salts in pure organic solvents have been used increasingly in industrial processes and devices as, e.g., in the fabrication of lithium-ion batteries involving different types of carbonates as the solvent [3], of wet double-layer capacitors and supercapacitors, and in electrodeposition, electroplating, etc. [4].

Experimental data about deviations from ideality in binary organic electrolyte solutions are by far not as plentiful as in the case of aqueous electrolytes. This is likely partly due to the fact that this type of solution is not found in nature. Moreover careful experiments require the use of absolutely dry salts and solvents, which may not be easy to achieve. Furthermore the solubility of common salts is generally limited in organic solvents. They are not as good solvents as water for salts.

\footnotetext{
${ }^{*}$ Corresponding author

Email address: jpsimonin@gmail.com. Tel. +33 144273190; Fax +33 144273228. (Jean-Pierre Simonin )
} 
Seminal works about such systems were apparently published at the beginning of the 20th century. They dealt with vapor-liquid equilibria (VLE) of alcoholic salt solutions. Seemingly one of these first experimental studies was reported in 1914 by Tower and Germann [5] about VLE of methanol and ethanol salt solutions at $15^{\circ} \mathrm{C}$. Then Hayward and Perman investigated in 1931 the vapor pressures of alcoholic solutions of calcium chloride at various temperatures from 20 to $60^{\circ} \mathrm{C}$ [6]. This work was pursued in 1981 by Mar and Carling [7]. After these first publications the study of deviations from ideality in (anhydrous) alcohols, and then other pure organic solvents, has been developed for a number of salts (see section 2).

Efforts have also been dedicated to the modeling of the deviations from ideality for these non-aqueous ionic solutions $[8,9,10,11]$. These models were mostly proposed at the McMillan-Mayer (MM) level of description [12] which is the generalization of the concept introduced van't Hoff according to which a dilute solution may be viewed as an ideal gas of solute. The MM theory offers a rigorous framework that allows one to consider concentrated solutions and non-idealities. At the MM level of description the chemical potential of the solvent is kept constant by exerting a pressure on the solution (amounting to the osmotic pressure as in van't Hoff theory) $[13,14,15]$, and the solute particles interact through solvent-averaged interactions $[12,16]$. Other modeling attempts have been proposed in which the solvent was explicitly taken into account, within the SAFT framework, in the case of alcohols as the solvent $[17,18]$. These models involved the use of 7 SAFT parameters to describe the properties of the alcohol alone, and 2 specific parameters for every cation and anion.

Because the dielectric constant of organic solvents is generally lower than that of water, cation-anion attraction and therefore ion pairing are expected to be enhanced as compared to aqueous solutions for a given salt. The most appealing and successful model applied to non-aqueous ionic solutions has certainly been the so-called chemical model (CM) promoted by Barthel and collaborators [19, 20, 21, 22, 23, 24] in which a part of the ions is supposed to form ion pairs and this process is assumed to obey a mass action law (MAL). The activity coefficient of the free ions is calculated within the framework of the Debye-Hückel (DH) theory. The latter feature limits the applicability of the CM to dilute solutions, typically below 0.1M. It has been applied to a number of salts, such as alkali halides and perchlorates, in various solvents (alcohols, acetone, acetonitrile,...). Apart from the CM, the Pitzer model has been utilized to represent osmotic and activity coefficients up to high concentrations [22, 24, 25]. Another class of model that has been used in the literature is the mean spherical approximation (MSA) [10], and the associative MSA (AMSA) [11, 26]. The MSA has similarities with the DH theory, but it accounts for excluded volume effects in a better way than the DH theory does [27]. Consequently models based on the MSA should be applicable to solutions more concentrated than within the DH framework. The MSA and the AMSA have been utilized to describe the properties of organic ionic solutions in which ion pairing was expected on the basis of conductivity experiments $[10,11,26]$. In the case of the MSA $[10,11,26]$ association was introduced in the same way as in the CM by introducing a MAL for ion pairs and deviations from ideality were estimated within the MSA (in lieu of the DH theory in the CM). In the AMSA $[11,26]$ cation-anion pairing is accounted for 
explicitly in the model by means of the Wertheim theory $[28,29]$ for association (which is also employed

in SAFT models), which introduces extra terms in the expressions of the activity and osmotic coefficients. The MSA combined with a MAL for the formation of ion pairs (MSA-MAL model) has been employed for a representation of the mean salt activity coefficients at $25^{\circ} \mathrm{C}$ of sodium halides and perchlorate and of tetrabutylammonium bromide, iodide and perchlorate in methanol up to concentrations ranging from $0.14 \mathrm{M}$ to $1.1 \mathrm{M}$ [10], and of lithium perchlorate in acetonitrile up to 0.9M [26]. The AMSA was utilized to represent the osmotic coefficient for solutions of a few tetraalkylammonium bromides in acetone and ethanol, of bispiperidinium bromide in ethanol, and of $\mathrm{LiClO}_{4}$ in acetone, acetonitrile and 2-propanol, up to typical concentrations of $0.5 \mathrm{M}-0.9 \mathrm{M}[11,26]$. A modified version of the AMSA was also proposed in order to include the effect of trimers and tetramers that are present in organic solvents of very low dielectric constant [11].

In this work, we use a model called the binding mean spherical approximation (BiMSA) [30, 31] which is equivalent to AMSA in the case of the formation of pairs. In this model it is considered that two unlike free ions may stick to each other to form an ion pair. In the past we have used the BiMSA to describe deviations from ideality in aqueous ionic solutions that exhibit ionic association [32, 33, 34].

The first aim of the present work was to examine whether it is possible to apply also this model to the case of organic electrolyte solutions, in a systematic way and for a greater number of systems (as we have been done before in the case of aqueous solutions $[35,32])$. This meant in particular: Can the thermodynamic description be done up to the maximum concentrations to which data are available ? If so is it possible to find consistent values for cation sizes in a given organic solvent? Finally, how do the regressed association constants compare with literature values determined from conductivity experiments ?

The remainder of this article is organized as follows. In the next section the available literature in which experimental data may be found is reviewed. Then a theoretical section presents the BiMSA model and the main features of an analysis proposed by Fawcett for the solvation of ions in a solvent [36]. The fourth section is dedicated to the presentation of the results and to their discussion. Finally the last section contains a summary of this work and some concluding remarks and prospects.

\section{Experimental thermodynamic data in the literature}

The thermodynamic properties of organic electrolyte solutions have been investigated by measuring vapor pressures (or vapor pressure lowering in practice) above solutions. Organic solvents capable of dissolving ions in substantial amounts may be classified into two main categories: protic, and dipolar aprotic solvents [19]. The first category includes water and alcohols, and the second acetone and acetonitrile, inter alia.

Protic solvents may solvate cations through two types of interaction: the first one is between the cation and the solvent dipole, and the second one is between the cation and the lone electrons on the oxygen atom of the solvent molecule. Anions may be solvated through hydrogen bonding [37,38]. At the same time, in water, the residence time of water molecules in the vicinity of anions has been shown to be several orders of magnitude shorter than close to cations [37]. Thus, in protic solvents in general, the solvation of anions 
is likely to be much weaker than that of cations. Dipolar aprotic solvents may stabilize cations through ion-dipole attraction. The solvation of anions in this type of solvent is not as clear.

Vapor pressure measurements have been carried out at $25^{\circ} \mathrm{C}$ above solutions of alkali halides and perchlorates in methanol [20, 22, 39, 40, 41, 42, 43, 44, 45], in ethanol [21, 22, 24, 46], and in 2-propanol [21, 22, 47]. Other measurements were carried out at the same temperature on the 2-1 salts calcium chloride and nitrate in methanol and ethanol $[48,49]$, on tetraalkylammonium salts in methanol [50], and on some more unusual salts such as tetramethylguanidinium chloride and perchlorate in ethanol [51]. Let us note here that the interest of $\mathrm{CaCl}_{2}$-methanol and ethanol systems for adsorption refrigeration and thermal energy storage has been highlighted lately[52, 53].

Besides alcohols, various (dipolar) aprotic solvents have been employed in thermodynamic vapor pressure experiments. These systems included solutions of $\mathrm{LiBr}$ and $\mathrm{LiClO}_{4}$ in acetone [23, 54], of $\mathrm{LiBr}, \mathrm{LiClO}_{4}$ and $\mathrm{NaI}$ in acetonitrile $[21,54,55]$ and of $\mathrm{LiClO}_{4}$ in dimethoxyethane (DME) and dimethylcarbonate (DMC) [54]. $\mathrm{LiClO}_{4}$ is an interesting salt because it is quite soluble in organic solvents [54]. The solvents used in the experiments provided a wide range of dielectric constants (see Table 1) going from 32.6 for methanol to as low as 3.1 for DMC. Let us recall that ion-pairing is expected to increase when the solvent permittivity is decreased.

No thermodynamic data could be found in the literature or within the ELDATA databank [56] about salts in other common solvents like dioxane or propylene carbonate.

\section{Modeling}

\subsection{The BiMSA model}

We first present briefly the main features of the basic MSA model for strong electrolytes [27, 57]. The theory is developed at the MM level of solutions [12]. In this model an electrolyte solution is modeled as charged hard spheres (the ions) placed in a dielectric continuum (the solvent). The ions may have different diameters. As compared to the Debye-Hückel (DH) theory, the MSA accounts in a consistent way for the effect of the minimum distances of approach (excluded volume) between the ions in the cloud around an ion (not only with respect to a central ion as the DH theory does) [27]. Consequently, it better describes the distribution of ions about a given ion in concentrated solutions. For these reasons, although this has been questioned sometimes in the literature [58], it seems preferable to use the MSA for a description of electrolyte solutions at high concentrations. Similarly to the DH model, the MSA is a linearized theory which provides analytic expressions. At the MM level, the diameter of an ion is expected to reflect its degree of solvation. Then it should be appreciably larger than its crystallographic diameter if the ion is strongly solvated. On the other hand, it should be of the same magnitude if the ion is weakly solvated, which is the case of monovalent anions in water [37, 38].

The BiMSA theory $[30,31]$ accounts for the association of spherical ions within the framework of the Wertheim theory in which the spheres possess binding sites at their surface [59]. The sites on unlike ions 
interact through highly directional attractive forces (as in SAFT models). After averaging on the orientations of the spheres, the potential $u_{i j}^{a t t r}(r)$ between two particles $i$ and $j$ is given by [30],

$$
\exp \left[-\beta u_{i j}^{a t t r}(r)\right]=\mathcal{B}_{i j} \delta\left(r-\sigma_{i j}\right)
$$

in which $\delta$ is the Dirac distribution, $\sigma_{i j}$ is the minimum approach distance between $i$ and $j$, and $\mathcal{B}_{i j}$ is the strength of this 'sticky' interaction.

In the BiMSA model a pair is defined as two unlike ions being in contact. The association scheme is sketched in Figure 1. In this respect it should be also noted that the effect of electrostatic forces on cation-

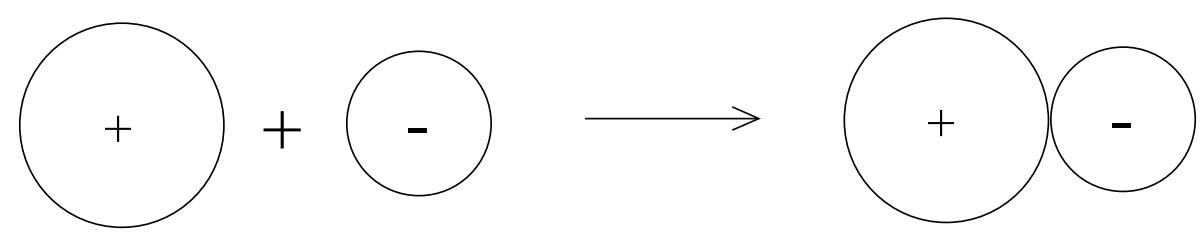

Figure 1: Association of two ions forming a pair.

anion association is consistently taken into account in the model. This effect appears in the expression of the cation-anion contact probability which is composed of a HS and an electrostatic contribution (see Eq. 69 of Ref. [31] in which the exponential approximation is used). Interestingly, this feature thus accounts for the influence of electrostatic screening on ion-pairing. It brings a contribution in the Helmholtz energy of the system and in the deviations from ideality of the solution.

Application of this model has been presented in previous work for associated aqueous ionic solutions $[32,34]$.

The valences, diameters and total number densities of the ions are $z_{+}, z_{-}, \sigma_{+}, \sigma_{-}, \rho_{+}, \rho_{-}$, respectively. We denote by $\alpha_{+}$and $\alpha_{-}$the unbound ion fractions.

We will recall here the main formulas useful for this work.

The model includes a mass action law (MAL) at the MM level as [31, 34],

$$
K_{0} \equiv \frac{\rho_{P}}{\left(\rho_{+} \alpha_{+}\right)\left(\rho_{-} \alpha_{-}\right)}=K g_{c}^{H S} \exp \left[-2 \lambda \frac{z_{+}^{\prime} z_{-}^{\prime}}{\sigma_{P}}+2 \lambda_{0} \frac{z_{+} z_{-}}{\sigma_{P, 0}}\right]
$$

in which $K$ is the thermodynamic association constant (related to the parameter $\mathcal{B}$ in Eq. 1), $\rho_{P}$ is the pair number density, $g_{c}^{H S}$ is the contact radial distribution function for the fluid of neutral hard spheres (HS) and,

$$
\begin{gathered}
z_{i}^{\prime} \equiv\left(z_{i}-\eta \sigma_{i}^{2}\right) /\left(1+\Gamma \sigma_{i}\right) \\
\lambda \equiv \beta e^{2} /\left(4 \pi \varepsilon_{0} \varepsilon\right) \\
\sigma_{P} \equiv \sigma_{+}+\sigma_{-}
\end{gathered}
$$

where $\lambda$ is the Bjerrum distance, $\lambda_{0}$ and $\sigma_{P, 0}$ are the value of $\lambda$ and $\sigma_{P}$ at infinite dilution, $\eta$ and $\Gamma$ are classical MSA parameters defined below, $\varepsilon_{0}$ is the permittivity of a vacuum, and $\varepsilon$ is the relative permittivity of solution. 
Note that Eq. 2 differs slightly from the expression originally taken in ref. [32]. It better takes into account the infinite dilution reference state [34].

For a given $K$, the pair number density is deduced from Eq. 2,

$$
\rho_{P}=\frac{2 K_{0} \rho_{+} \rho_{-}}{1+K_{0} \rho_{t}+\left[1+2 K_{0} \rho_{t}+K_{0}^{2}\left(\rho_{+}-\rho_{-}\right)^{2}\right]^{1 / 2}}
$$

with $\rho_{t} \equiv \rho_{+}+\rho_{-}$the total number density of ions, including free ions as well as those present in ion pairs.

The MSA parameters $\Gamma$ (the MSA screening parameter, analog of the DH screening parameter $\kappa$ ) and $\eta$ satisfy the following relations,

$$
\begin{aligned}
& \frac{\Gamma^{2}}{\pi \lambda}=\sum_{k=+,-} \rho_{k} z_{k}^{\prime 2}+\frac{2 \rho_{P}}{\sigma_{P}}\left(\frac{\sigma_{+}}{1+\Gamma \sigma_{+}}+\frac{\sigma_{-}}{1+\Gamma \sigma_{-}}\right) z_{+}^{\prime} z_{-}^{\prime} \\
& \eta=\frac{\pi}{2 \Delta \Omega}\left[\sum_{k=+,-} \frac{\rho_{k} \sigma_{k} z_{k}}{1+\Gamma \sigma_{k}}+\frac{\rho_{P}}{\sigma_{P}} \frac{z_{+} \sigma_{-}^{2}+z_{-} \sigma_{+}^{2}}{\left(1+\Gamma \sigma_{+}\right)\left(1+\Gamma \sigma_{-}\right)}\right]
\end{aligned}
$$

with

$$
\Omega=1+\frac{\pi}{2 \Delta}\left[\sum_{k=+,-} \frac{\rho_{k} \sigma_{k}^{3}}{1+\Gamma \sigma_{k}}+\frac{2 \rho_{P}}{\sigma_{P}} \frac{\sigma_{+}^{2} \sigma_{-}^{2}}{\left(1+\Gamma \sigma_{+}\right)\left(1+\Gamma \sigma_{-}\right)}\right]
$$

and

$$
\Delta=1-\frac{\pi}{6} \sum_{k} \rho_{k} \sigma_{k}^{3}
$$

is the fraction of space not occupied by the solute. Eqs. 5 and 6 constitute two coupled equations that can be easily solved numerically by iterations, using Eqs. 2 and 4 for a given value of $K$ and starting with the initial values $\Gamma_{0}=\kappa / 2$ and $\rho_{P}=0$ in Eqs 6 and 7. These values for $\Gamma$ and $\eta$ are then inserted into Eq. 5 and the same procedure is repeated until convergence.

The excess electrostatic MSA internal energy per volume unit is,

$$
\beta \Delta U^{M S A}=\beta \Delta U_{0}^{M S A}+\lambda \frac{\rho_{P}}{\sigma_{P}}\left(\frac{z_{+} z_{-}^{\prime}}{1+\Gamma \sigma_{+}}+\frac{z_{-} z_{+}^{\prime}}{1+\Gamma \sigma_{-}}\right)
$$

with

$$
\beta \Delta U_{0}^{M S A}=-\lambda \sum_{i=+,-} \rho_{i} z_{i} \frac{\Gamma z_{i}+\eta \sigma_{i}}{1+\Gamma \sigma_{i}}
$$

the excess internal energy in the absence of association. The excess MSA Helmholtz energy $A$ per volume unit is,

$$
\beta \Delta A^{M S A}=\beta \Delta U^{M S A}+\frac{\Gamma^{3}}{3 \pi}+\beta \Delta A^{M A L}-2 \lambda \frac{\rho_{P}}{\sigma_{P}} z_{+}^{\prime} z_{-}^{\prime}
$$

In this equation the MAL contribution is given by

$$
\beta \Delta A^{M A L}=\sum_{k=+,-} \rho_{k} \ln \alpha_{k}+\rho_{P}
$$

The excess osmotic coefficient is expressed as,

$$
\Delta \phi^{M S A}=\Delta \phi_{0}^{M S A}+\Delta \phi_{\sigma_{+}}+\Delta \phi_{\varepsilon}
$$


where the last two terms account for the possible variation of the cation diameter and of the solution permittivity with salt concentration. One has,

$$
\begin{gathered}
\Delta \phi_{0}^{M S A}=\Delta \phi_{0}^{e l}+\Delta \phi_{0}^{M A L} \\
\Delta \phi_{0}^{e l}=-\frac{\Gamma^{3}}{3 \pi \rho_{t}}-\frac{\lambda}{\rho_{t}} \frac{2}{\pi} \eta^{2} \\
\Delta \phi_{0}^{M A L}=-\frac{\rho_{P}}{\rho_{t}}\left(1+\rho_{t} \frac{\partial \ln g_{c}^{H S}}{\partial \rho_{t}}\right)
\end{gathered}
$$

and

$$
\begin{gathered}
\Delta \phi_{\sigma_{+}}=\frac{1}{\rho_{t}}\left[\frac{\partial \beta \Delta A^{M S A}}{\partial \sigma_{+}}\right]_{\Gamma} \times \mathrm{D}\left(\sigma_{+}\right) \\
\Delta \phi_{\varepsilon}=\frac{\beta \Delta U^{M S A}}{\rho_{t}} \varepsilon \mathrm{D}\left(\varepsilon^{-1}\right)
\end{gathered}
$$

with

$$
\mathrm{D} \equiv C_{S} \frac{\partial}{\partial C_{S}}
$$

in which $C_{S}$ is the salt concentration. One has,

$$
\left[\frac{\partial \beta \Delta A^{M S A}}{\partial \sigma_{+}}\right]_{\Gamma}=\left[\frac{\partial \beta \Delta U^{M S A}}{\partial \sigma_{+}}\right]_{\Gamma, \rho_{P}}-\rho_{P}\left[\frac{\partial \ln g_{c}^{H S}}{\partial \sigma_{+}}+2 \frac{\lambda z_{+}^{\prime} z_{-}^{\prime}}{\sigma_{P}^{2}}\right]
$$

with

$$
\left[\frac{\partial \beta \Delta U^{M S A}}{\partial \sigma_{+}}\right]_{\Gamma, \rho_{P}}=\lambda \rho_{+} \frac{z_{+}^{\prime}\left[\Gamma^{2}\left(z_{+}+\eta \sigma_{+}^{2}\right)-2 \eta\right]}{1+\Gamma \sigma_{+}}-\lambda \frac{2 \rho_{P}}{\sigma_{P}} \frac{\Gamma\left(z_{+}+\eta \sigma_{+}^{2}\right)+2 \eta \sigma_{+}}{\left(1+\Gamma \sigma_{+}\right)^{2}} z_{-}^{\prime}
$$

The expression of $g_{c}^{H S}$ and of its derivatives may be found in refs. [32, 34].

The total osmotic coefficient at MM level is,

$$
\phi=1+\Delta \phi^{M S A}+\Delta \phi^{H S}
$$

in which $\Delta \phi^{H S}$ is the hard sphere contribution that can be calculated from the Carnahan-Starling expression, as described elsewhere [60].

For comparison with experimental data it is needed to convert the value obtained for $\phi$ at the MM level to the experimental level (the Lewis-Randall (LR) level). This may be done by using the so-called MMto-LR conversion formula as explained elsewhere $[14,15,60]$, that requires only the availability of solution density data.

The excess MSA mean activity coefficient can be obtained simply from the formula

$$
\Delta \ln \gamma_{ \pm}^{M S A}=\frac{\beta \Delta A^{M S A}}{\rho_{t}}+\Delta \phi^{M S A}
$$

The BiMSA contributions to the osmotic and activity coefficients, Eqs. 12 and 22, naturally satisfy the Gibbs-Duhem relation. 
As in previous work $[34,60,35]$ it will be assumed that the anion size may be kept constant and that the diameter of the cation and the inverse of solution relative permittivity vary as linear functions of the concentration,

$$
\begin{gathered}
\sigma_{+}=\sigma_{+}^{(0)}+\sigma_{S}^{(1)} C_{S} \\
\varepsilon^{-1}=\varepsilon_{\text {org }}^{-1}\left(1+\alpha C_{S}\right)
\end{gathered}
$$

150

\subsection{Analysis of ion solvation in organic solvents within the ion-dipole MSA}

It has been shown that anions in water are solvated through hydrogen bonding [37, 38]. Alcohols may be expected to solvate anions in the same way because they also offer the possibility of H-bonding [10]. This is not the case of aprotic solvents.

Fawcett proposed a method to analyze the solvation of simple cations and anions [36] in a solvent in the framework of the ion-dipole MSA [63, 64]. In the latter a solvent molecule is represented as a hard sphere with an embedded point dipole at its center. Then, within the ion-dipole MSA model applied to the present study, the molar solvation Gibbs energy of an ion, $\Delta G$, should satisfy the original Born equation in the form,

$$
\Delta G=\frac{\mathcal{N} z^{2} e^{2} f_{d d}}{4 \pi \varepsilon_{0} \sigma_{B}}\left(1-\frac{1}{\varepsilon_{\text {org }}}\right)
$$

with $\mathcal{N}$ the Avogadro number and $z$ the ion valency. Moreover, $f_{d d}$ is a parameter accounting for the effect of dipole-dipole interactions in the solvation process and $\sigma_{B}$ is the Born diameter. In the case of cations, one has $[36] f_{d d}=1$ and,

$$
\sigma_{B}=\sigma_{c r}+\Delta_{o r g}
$$




\begin{tabular}{|c|c|c|c|c|}
\hline Solvent & $\begin{array}{c}d_{o r g} \\
/\left(\mathrm{kg} \mathrm{m}^{-3}\right)\end{array}$ & $\begin{array}{c}\eta_{\text {org }} \\
/\left(10^{-3} \mathrm{~kg} \mathrm{~m}^{-1} \mathrm{~s}^{-1}\right)\end{array}$ & $\varepsilon_{\text {org }}$ & $\begin{array}{c}m_{\text {org }} \\
/ \text { Debye }^{a}\end{array}$ \\
\hline Methanol & 786.36 & 0.542 & 32.63 & $1.70^{b}$ \\
\hline Ethanol & 784.95 & 1.087 & 24.35 & $1.69^{b}$ \\
\hline 2-propanol & 780.97 & 2.08 & 19.40 & $1.66^{c}$ \\
\hline Acetone & 784.35 & 0.303 & 20.56 & $2.88^{b}$ \\
\hline Acetonitrile & 776.75 & 0.341 & 35.95 & $3.91^{c}$ \\
\hline
\end{tabular}

${ }^{a} 1$ Debye $=3.3356 \times 10^{-30} \mathrm{C} \mathrm{m} ; ;^{b}$ Ref. [66]; ${ }^{c}$ Ref. [67].

in which $\sigma_{c r}$ is the crystallographic diameter of the ion and $\Delta_{\text {org }}$ is a distance characteristic of the solvent Born theory (in which $\Delta_{\text {org }} \equiv 0$ ) but it has a granular structure.

In the case of anions, one expects to have $f_{d d}<1$ and $\Delta_{\text {org }}=0\left(\sigma_{B}=\sigma_{c r}\right)$.

By virtue of Eq. 28, Eq. 27 may be rewritten as,

$$
-\frac{\mathcal{N} z^{2} e^{2}\left(\varepsilon_{\text {org }}-1\right)}{4 \pi \varepsilon_{0} \varepsilon_{\text {org }} \Delta G}=\frac{1}{f_{d d}} \sigma_{c r}+\frac{\Delta_{\text {org }}}{f_{d d}}
$$

which indicates that a plot of the l.h.s. of this equation as a function of $\sigma_{c r}$ for various (simple) ions should give a straight line and values for $f_{d d}$ and $\Delta_{\text {org }}$ by linear regression.

This has been done by Fawcett for monovalent cations and anions in water [36], which confirmed the expectation that $f_{d d}=1$ for cations and $f_{d d}<1$ for anions. Furthermore he found an optimum value $\Delta_{\text {org }}=$ $0.49 \AA$ for cations and he indeed obtained $\Delta_{\text {org }} \sim 0$ for anions.

In the present work, the same method of analysis has been applied to the solvation of anions in some organic solvents in order to gain some insight into the solvation of these ions.

\section{Preliminary results}

In this section we present results needed in the description of the thermodynamic properties of organic electrolyte solutions within the BiMSA model.

\subsection{Data for pure solvents and electrolyte solutions densities}

The following data will be useful below. The densities $\left(d_{\text {org }}\right)$, dynamic viscosities $\left(\eta_{\text {org }}\right)$, dielectric

constants $\left(\varepsilon_{\text {org }}\right)$ and dipole moments of molecules in the gas phase $\left(m_{\text {org }}\right)$ of the pure solvents at $25^{\circ} \mathrm{C}$ are collected in Table 1. They were all taken from ref. [65].

The densities of the ionic solutions are needed in order to perform the MM-to-Lewis-Randall conversion $[14,15,60]$. Experimental data were regressed according to the following formula,

$$
d=d_{\text {org }}+d_{1} C_{S}-d_{2} C_{S}^{3 / 2}
$$


as has been done in the case of aqueous solutions [68]. Let us note that the parameter $d_{1}$ is given by [68],

$$
d_{1}=M_{S}-d_{\text {org }} V_{S}^{0}
$$

in which $M_{S}$ is the molar mass of the salt and $V_{S}^{0}$ is its partial molar volume at infinite dilution.

The values of the parameters $d_{1}$ and $d_{2}$ are given in Table 2. No density data could be found in the case of solutions of $\mathrm{LiCl}$ in 2-propanol. For this solution the values of $d_{1}$ and $d_{2}$ in Table 2 were estimated empirically from the values for solutions of $\mathrm{LiCl}$ in methanol and ethanol. Only one density value was retrieved in the case of $\mathrm{NaI}$ in 2-propanol at saturation [69]. In this case the value of $d_{1}$ was estimated from those for $\mathrm{NaI}$ in methanol and ethanol, and that of $d_{2}$ was deduced from the density at saturation.

It may be noticed in Table 2 that most lithium halides exhibit $d_{1}$ values that are larger than the molar mass of the salt, $M_{S}$. By virtue of Eq. 30, this entails that the partial molar volumes of these salts in these solvents, $V_{S}^{0}$, are negative. We also note that this is not so for these same salts in water, for which $d_{1}$ is much smaller than $M_{S}$ and thus $V_{S}^{0}$ is positive $\left(d_{1} \sim 23.6 \mathrm{~g} \mathrm{~mol}^{-1}\right.$ and $M_{S} \sim 42.4 \mathrm{~g} \mathrm{~mol}^{-1}$ for LiCl, and $d_{1} \sim 60.5 \mathrm{~g} \mathrm{~mol}^{-1}$ and $M_{S} \sim 86.8 \mathrm{~g} \mathrm{~mol}^{-1}$ for $\left.\mathrm{LiBr}\right)$. These two remarks indicate that lithium halides salts are strongly solvated in the organic solvents considered here. 


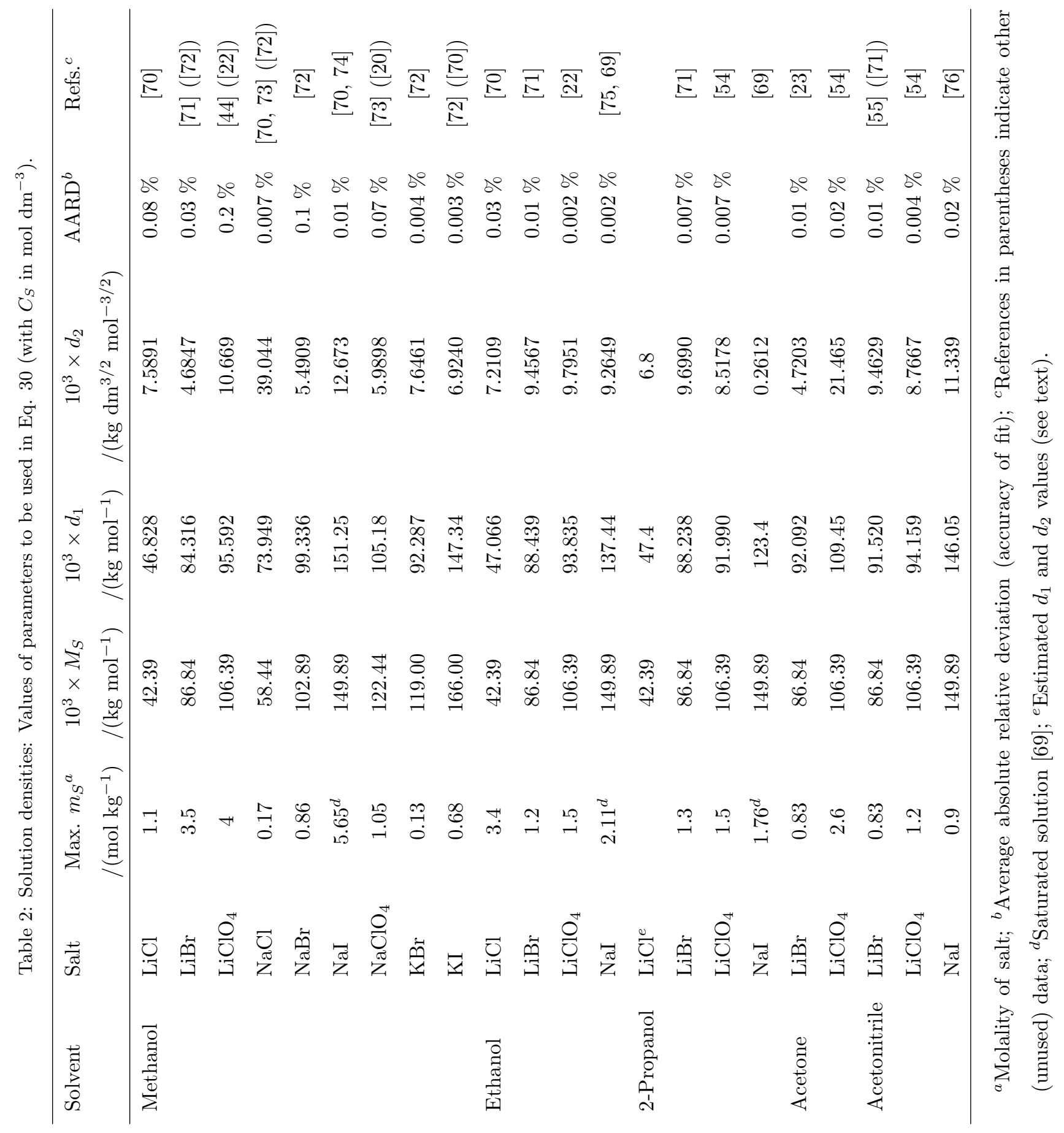




\subsection{Stokes hydrodynamic diameters of ions from conductivity experiments} considered in this work. They will be useful in the treatment below.

The hydrodynamic diameter of an ion is the diameter of a rigid sphere that would have the same diffusion coefficient (or equivalently the same ionic mobility) as the ion. The diameters were derived from Stokes' law [77] for no-slip condition of the fluid at the surface of the sphere,

$$
\sigma_{\text {hyd }}=2 \frac{|z| \mathcal{N} e^{2}}{6 \pi \eta_{\text {org }} \lambda_{0}}=\frac{16.404|z|}{\eta_{\text {org }} \lambda_{0}}
$$

in which $\lambda_{0}$ is the limiting equivalent conductance of the ion (expressed in $\mathrm{cm}^{2} \Omega^{-1} \mathrm{~mol}^{-1}$ ), and the solvent viscosity $\eta_{\text {org }}$ (expressed in SI units) was taken from Table 1.

The $\lambda_{0}$ values and the Stokes diameters obtained from Eq. 32 for the cations and anions considered in this work are gathered in Table 3. Unfortunately no conductivity data could be found in the case of 2-propanol. Values for ions in water are recalled in this table.

The numerical values of Table 3 may be commented as follows.

The hydrodynamic diameters (HD's) of $\mathrm{Li}^{+}$and $\mathrm{Na}^{+}$in water are appreciably larger than their crystallographic diameters (CD's) because of the effect of their hydration shell. On the other hand the HD's of $\mathrm{K}^{+}$and of anions in water are smaller than the corresponding CD's. This outcome is likely due to the fact that Stokes law is not accurate for spherical ions whose of size comparable to that of the solvent, as is the case for these weakly hydrated ions. This suggests also that Stokes law underestimates the effective size of an ion in water.

The HD's of cations in the organic solvents are all clearly larger than their CD's, and also larger than their HD's in water. This seems to indicate that the solvation shells of cations in the solvents are thicker than their hydration shells. Contrary to what occurs in water, the HD's of $\mathrm{Br}^{-}$and $\mathrm{I}^{-}$in the aprotic solvents acetone and acetonitrile are a bit greater than the CD's. It is striking that the $\mathrm{HD}^{\text {'s }}$ of $\mathrm{ClO}_{4}^{-}$in these solvents, 4.57 and $4.65 \AA$ respectively, are just a bit larger than its thermochemical diameter of 4.52 $\AA$. This is in contrast with the case of water for which the $\mathrm{HD}$ of the $\mathrm{ClO}_{4}^{-}$anion $(2.74 \AA)$ is much smaller that its thermochemical diameter.

In the next section, some information about the solvation of anions in the solvents is obtained within the ion-dipole MSA framework.

\subsection{Solvation of anions in organic solvents.}

The analysis proposed by Fawcett and described in section 3.2 was applied to the solvation of halide anions (except the fluoride ion) in a few organic solvents, namely methanol, acetone and acetonitrile. Values for the standard Gibbs energies of transfer of single ions from water to a few solvents (methanol, acetone and acetonitrile) were obtained from the work of Conway [88]. The values of the single ion Gibbs energies of hydration were taken from the same paper by Fawcett [36]. Combination of these latter two quantities provided the single ion Gibbs energies of solvation in the organic solvents. The Shannon and Prewitt values 
Table 3: Limiting equivalent conductances $\left(\lambda_{0}\right)$, hydrodynamic Stokes diameters $\left(\sigma_{\text {hyd }}\right)$ and crystallographic diameters of ions.

\begin{tabular}{|c|c|c|c|c|c|}
\hline Solvent & Ion & $\begin{array}{c}\lambda_{0} \\
/\left(\mathrm{cm}^{2} \Omega^{-1} \mathrm{~mol}^{-1}\right)\end{array}$ & $\begin{array}{c}\sigma_{\text {hyd }} \\
/ \AA\end{array}$ & $\begin{array}{c}\sigma_{c r}^{a} \\
/ \AA\end{array}$ & Refs. $^{b}$ \\
\hline \multirow[t]{7}{*}{ Water } & $\mathrm{Li}^{+}$ & 38.68 & 4.76 & 1.80 & {$[77]$} \\
\hline & $\mathrm{Na}^{+}$ & 50.10 & 3.68 & 2.32 & {$[77]$} \\
\hline & $\mathrm{K}^{+}$ & 73.50 & 2.51 & 3.04 & {$[77]$} \\
\hline & $\mathrm{Cl}^{-}$ & 76.35 & 2.41 & 3.34 & {$[77]$} \\
\hline & $\mathrm{Br}^{-}$ & 78.14 & 2.36 & 3.64 & {$[77]$} \\
\hline & $\mathrm{I}^{-}$ & 76.84 & 2.40 & 4.12 & {$[77]$} \\
\hline & $\mathrm{ClO}_{4}^{-}$ & 67.36 & 2.74 & $4.52^{c}$ & {$[77]$} \\
\hline \multirow[t]{3}{*}{ Methanol } & $\mathrm{Li}^{+}$ & 39.82 & 7.56 & 1.80 & {$[78]$} \\
\hline & $\mathrm{Na}^{+}$ & $45.05,45.22$ & 6.65 & 2.32 & {$[79,78]$} \\
\hline & $\mathrm{K}^{+}$ & 52.40 & 5.74 & 3.04 & {$[78]$} \\
\hline \multirow[t]{2}{*}{ Ethanol } & $\mathrm{Li}^{+}$ & 17.05 & 8.87 & 1.80 & {$[80]$} \\
\hline & $\mathrm{Na}^{+}$ & 20.31 & 7.46 & 2.32 & {$[80]$} \\
\hline \multirow[t]{3}{*}{ Acetone } & $\mathrm{Li}^{+}$ & 72.52 & 7.46 & 1.80 & {$[81]$} \\
\hline & $\mathrm{Br}^{-}$ & 118.94 & 4.55 & 3.64 & {$[82]$} \\
\hline & $\mathrm{ClO}_{4}^{-}$ & 118.35 & 4.57 & 4.52 & {$[82]$} \\
\hline \multirow[t]{5}{*}{ Acetonitrile } & $\mathrm{Li}^{+}$ & 70.8 & 6.77 & 1.80 & {$[83,84]$} \\
\hline & $\mathrm{Na}^{+}$ & 77.3 & 6.20 & 2.32 & {$[84]$} \\
\hline & $\mathrm{Br}^{-}$ & 100.7 & 4.76 & 3.64 & {$[83,84]$} \\
\hline & $\mathrm{I}^{-}$ & 102.2 & 4.69 & 4.12 & {$[83,84]$} \\
\hline & $\mathrm{ClO}_{4}^{-}$ & 103.38 & 4.65 & 4.52 & {$[85]$} \\
\hline
\end{tabular}

${ }^{a}$ From ref. [86] for a coordination number of $6 ;{ }^{b}$ References for conductance values; ${ }^{c}$ Thermochemical value from ref. $[87,86]$. 
Table 4: Values of parameters $f_{d d}$ and $\Delta_{\text {org }}$ introduced in Eq. 27, obtained from linear fits using Eq. 29 in the case of the halide anions, $\mathrm{Cl}^{-}, \mathrm{Br}^{-}$and $\mathrm{I}^{-}$.

\begin{tabular}{lcc}
\hline Solvent & $f_{d d}$ & $\Delta_{\text {org }}(/ \AA)$ \\
\hline Water & $0.74^{a}$ & $0^{a}$ \\
Methanol & $0.726 \pm 0.011$ & $0.013 \pm 0.055$ \\
Acetone & $0.975 \pm 0.036$ & $1.55 \pm 0.19$ \\
Acetonitrile & $0.960 \pm 0.006$ & $1.61 \pm 0.03$ \\
\hline
\end{tabular}

${ }^{a}$ Results found by Fawcett [36]. $\sigma_{C l^{-}}=3.34 \AA, \sigma_{B r^{-}}=3.64 \AA$ and $\sigma_{I^{-}}=4.12 \AA$.

The results are presented in Table 4 and in Figure 2 in which the function $\psi \equiv-\mathcal{N} z^{2} e^{2}\left(\varepsilon_{\text {org }}-\right.$

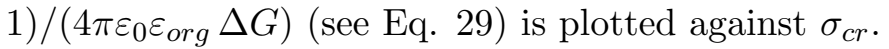

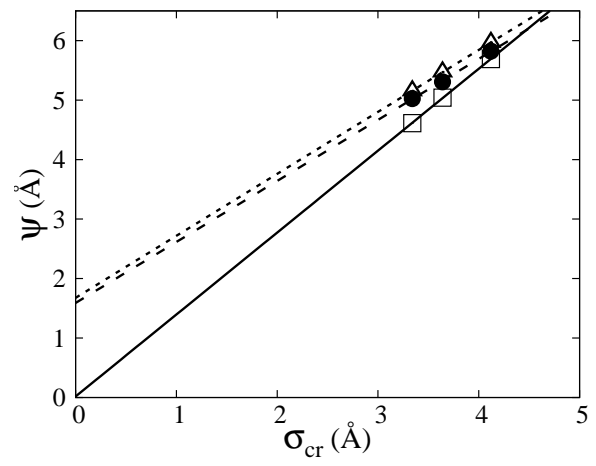

Figure 2: Plot of the l.h.s. of Eq. 29 (denoted by the symbol $\psi$ ) as a function of the crystallographic radius of the halide anions, $\mathrm{Cl}^{-}, \mathrm{Br}^{-}$and $\mathrm{I}^{-}$. Symbols: Ions in $(\square)$ methanol, $(\bullet)$ acetone, $(\triangle)$ acetonitrile. Straight lines show the results of two-parameter linear fits (see Table 4).

The results of Table 4 are striking. Two clearly distinct cases are observed: either $f_{d d}$ is significantly smaller than 1 and $\Delta_{\text {org }}$ is close to zero (case of water and methanol), or $f_{d d} \sim 1$ and $\Delta_{\text {org }}$ has a finite value (case of the aprotic solvents).

These results suggest that the solvation of simple anions in methanol is similar to that in water, with anions solvated through H-bonding, which is reflected in $f_{d d}$ being smaller than 1 and $\Delta_{\text {org }}$ being very small, as was the case for water in ref. [36]. According to the analysis of ref. [36] the fact that $f_{d d}<1$ indicates that dipole-dipole repulsive interactions significantly reduce the ion-dipole attractive energy, and $\Delta_{\text {org }} \sim 0$ points to a much less disruptive effect of anions on water structure than cations.

The results obtained for the solvents acetone and acetonitrile are in sharp contrast with those for methanol, as could be expected because these solvents are aprotic. Here one gets $f_{d d} \simeq 1$ and $\Delta_{\text {org }}$ has appreciable values of the order of $1.6 \AA$. This situation is similar to that of cations in water for which it 
Table 5: Values of infinite dilution cation diameters in water in MSA model [35] vs. Stokes diameters at $25^{\circ} \mathrm{C}$

\begin{tabular}{lcc}
\hline Ion & $\sigma_{\text {hyd }}(/ \AA)$ & $\sigma_{+}^{(0)}(/ \AA)$ \\
\hline $\mathrm{Li}^{+}$ & 4.76 & 5.43 \\
$\mathrm{Na}^{+}$ & 3.68 & 3.87 \\
$\mathrm{Mg}^{2+}$ & 6.95 & 6.71 \\
$\mathrm{Ca}^{2+}$ & 6.19 & 7.03 \\
$\mathrm{Sr}^{2+}$ & 6.20 & 6.69 \\
$\mathrm{Ba}^{2+}$ & 5.79 & 6.01 \\
\hline
\end{tabular}

was pointed out that $f_{d d} \sim 1$ suggests that dipole-dipole interactions (between water molecules) are not important in determining the solvation of cations. The result $\Delta_{\text {org }}>0$ suggests that the solvation of anions in acetone and acetonitrile might be mediated by ion-dipole interactions, and that it is stronger than in water. This view may be supported by the fact that these two organic molecules bear strong dipole moments of $2.88 \mathrm{D}$ and $3.91 \mathrm{D}$, respectively (see Table 1). As a consequence the effective diameter of anions in these two solvents, within the BiMSA theory at the MM level, should certainly be taken larger than their crystallographic value.

\section{Results from BiMSA model and discussion}

We now have to choose values for the anion diameters for input into the BiMSA model.

It has been seen in the preceding section that their solvation in the protic solvents (methanol, ethanol and 2-propanol) seems similar to that in water (through H-bonding). Therefore, as in previous work [32, 34, 35], the Pauling diameters were taken for the anions in these solvents, namely for $\mathrm{Cl}^{-}(3.62 \AA), \mathrm{Br}^{-}(3.90 \AA)$ and $\mathrm{I}^{-}(4.32 \AA)$. Moreover a value of $4.53 \AA$ (optimized in ref. [35]) was used for the perchlorate anion. This value is besides in excellent accord with the thermochemical value of $4.52 \AA[86,87]$.

The preceding section also has suggested that in the aprotic solvents acetone and acetonitrile anion solvation is similar to the solvation of cations in water. Besides, the results of Table 5 show some correlation between the cation diameter at infinite dilution, $\sigma_{+}^{(0)}$, and the hydrodynamic diameter. On this basis it was chosen to use the HD of anions in these solvents for their effective diameter in the BiMSA model.

Then the osmotic coefficient data were fitted within the BiMSA model by using Eq. 21 (which expresses $\phi$ at the MM level) and the MM-to-LR conversion $[14,15,60]$ in which the parametrization of the solution densities of Table 2 was utilized. No variation of the anion diameter with concentration was assumed because it was considered that the desolvation of the more solvated cation had the strongest effect on the thermodynamics of the solution. This description thus involves the use of 4 parameters, viz. $\sigma_{+}^{(0)}$ and $\sigma_{S}^{(1)}($ Eq. 23), $\alpha$ (Eq. 24) and the association constant $K$. These parameters were regressed by using a least-squares algorithm of the Marquardt type in a FORTRAN program.

Let us underline that data for salts in dimethoxyethane (DME) and dimethylcarbonate (DMC) [54] 
were not treated in this work because these solvents give rise to aggregates that go beyond ion-pair, with the formation of triple ions and "quadrupoles" [89, 90, 91]. As mentioned in the Introduction section, the influence of this type of association has been modeled within the AMSA [11].

The results of the adjustments are presented in Table 6 .

Let us underline that $\sigma_{+}^{(0)}$, the cation diameter at infinite dilution, should have a common value for all salts containing the same cation, in a given solvent. Actually this is a stringent requirement when adjustments are made up to high concentrations because in this case the sizes of the ions (and of the cation in particular) have a strong influence on the calculated deviations from ideality ( $\phi$ in the present case).

Moreover, besides a low value of the deviation (AARD in Table 6), a good fit should be characterized by values of $\sigma_{S}^{(1)}$ and $\alpha$ that are respectively negative and positive, and do not have unrealistic values. These latter two conditions express the fact that the cation diameter and the relative permittivity are expected to decrease with concentration if the model indeed has some physical meaning.

It is observed in Table 6 that these two conditions, $\sigma_{S}^{(1)}<0$ and $\alpha>0$, are fulfilled, which is a satisfactory outcome, and that the fits are generally of good accuracy. Overall, most values for $\sigma_{S}^{(1)}$ are of the same order of magnitude (of the order of -0.2 or -0.3 ). However, no clear trend emerges in the $\sigma_{S}^{(1)}$ and $\alpha$ values as a function of the nature of the salt or of another parameter characteristic of the system. Nonetheless, it is noticed that the higher $\sigma_{S}^{(1)}$ values are found in the case of lithium salts in ethanol in which the $\mathrm{Li}^{+}$ cation has the greater $\sigma_{+}^{(0)}$ value. Indeed this feature may be expected on the ground that the solvation shell of the biggest cation should shrink more rapidly when the salt concentration is increased, because then the amount of free solvent should drop more quickly.

The regressed values for $K$ were compared with data found in the literature, $K_{l i t}$. When the latter was expressed on the molal scale $\left(K_{l i t}^{(m)}\right)$ it was converted to the molar scale by using the formula, $K_{l i t}=$ $K_{\text {lit }}^{(m)} / d_{\text {org }}$, which may be obtained easily by expressing $K_{\text {lit }}$ and $K_{\text {lit }}^{(m)}$ as a function of the concentrations of the involved species, on molar and molal bases respectively, and using the relation $C_{i}=m_{i} d_{\text {org }}$ at infinite dilution. 


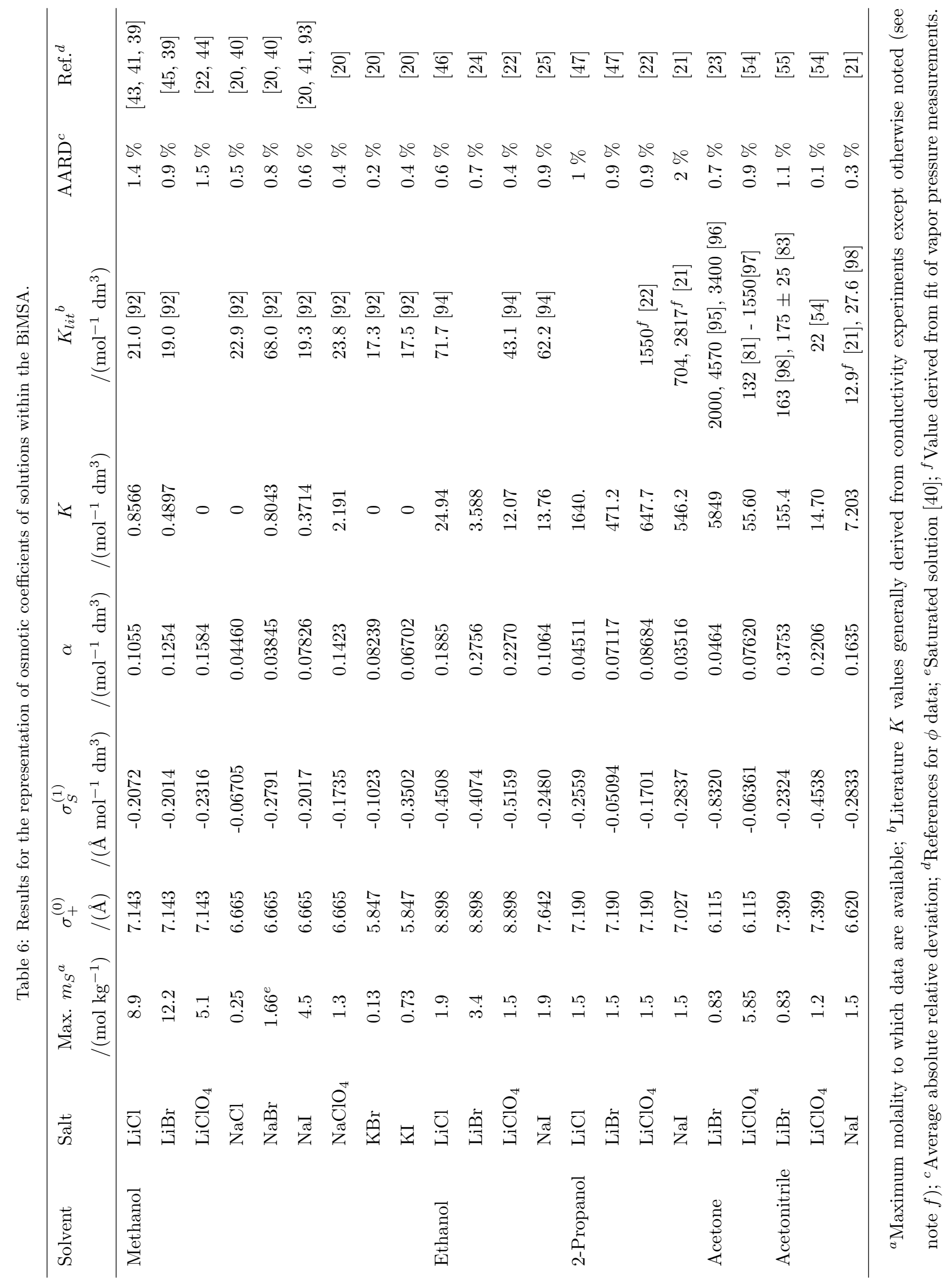


We now examine the results in more detail for each solvent. In each case the diameter at infinite dilution (DID) for a given cation, $\sigma_{+}^{(0)}$, is determined in a first step.

\subsection{Solutions in methanol}

Four-parameter fits of $\phi$ for solutions of $\mathrm{LiCl}$ and $\mathrm{LiBr}$ up to the highest concentrations of $8.9 \mathrm{~mol} \mathrm{~kg}^{-1}$ and $12.2 \mathrm{~mol} \mathrm{~kg}^{-1}$, respectively, yielded values of $7.152 \AA$ and $7.134 \AA$, respectively, for the DID. This agreement is a very satisfactory (and somewhat surprising) result. It must be noticed that these DID values are very constrained because the two maximum concentrations are quite high. As a consequence there is very little flexibility in the choice of the DID for this cation. The mean value of these two results for $\sigma_{+}^{(0)}$, $7.143 \AA$, was adopted for the DID of the $\mathrm{Li}^{+}$cation.

The results of the adjustments of $\phi$ are shown in Figures 3 and 4 for $\mathrm{LiCl}$ and $\mathrm{LiBr}$, respectively. It is unfortunate that few data are available at high concentration for these two salts. Moreover there are no experimental data in the case of $\mathrm{LiBr}$ in the region where the osmotic coefficient tops out.

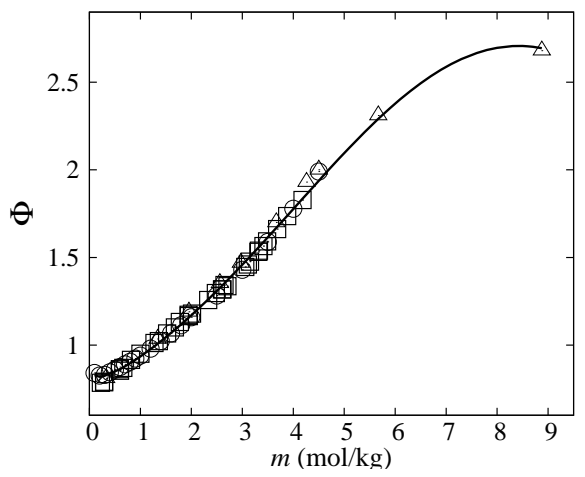

Figure 3: Osmotic coefficient for solutions of $\mathrm{LiCl}$ in methanol. Symbols: $(\bullet)$ data from ref. [43], $(\odot)$ data from ref. [41], $(\triangle)$ data from ref. [39]. Solid line: result from BiMSA model.

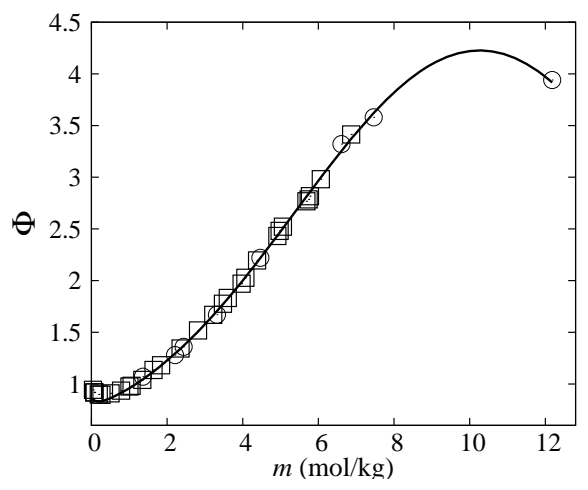

Figure 4: Osmotic coefficient for solutions of LiBr in methanol. Symbols: (๑) data from ref. [45], (๑) data from ref. [39]. Solid line: result from BiMSA model. 
The results for the mean salt activity coefficient, $\gamma_{ \pm}$, computed using Eq. 22 and Eq. 30 of Ref. [60] for the HS part, are displayed in Figure 5 in the case of $\mathrm{LiCl}$ and $\mathrm{LiBr}$. Let us note that no experimental values (e.g., obtained using an electrochemical method) are available for the activity coefficients of these salts.

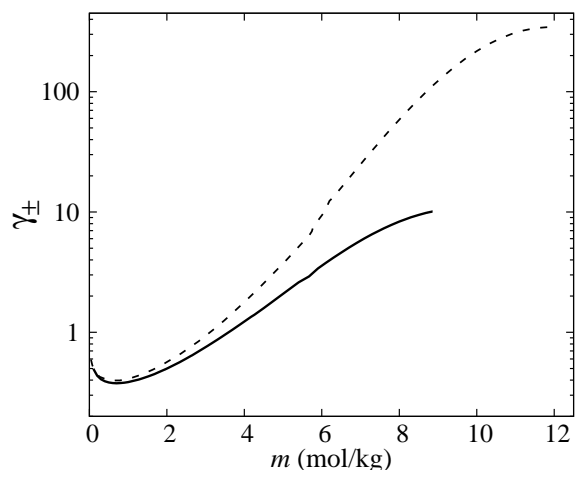

Figure 5: Mean salt activity coefficient computed using the BiMSA model for solutions of LiCl (solid line) and LiBr (dashed line) in methanol.

The DID of $\mathrm{Na}^{+}$was obtained from a fit of data for NaI that are available up to $4.5 \mathrm{~mol} \mathrm{~kg}^{-1}$.

The DID of $\mathrm{K}^{+}$was optimized by performing simultaneous fits of the data for $\mathrm{KBr}$ and $\mathrm{KI}$. It is noticed that the DID value for this cation $(5.847 \AA)$ is just a little larger than its hydrodynamic diameter (HD) in methanol $(5.74 \AA)$, which is in keeping with the correlation observed for cations in water (see Table 5).

\subsection{Solutions in ethanol}

The DID of $\mathrm{Li}^{+}$was taken from the fit of $\phi$ in the case of $\mathrm{LiBr}, \sigma_{+}^{(0)}=8.898 \AA$, because, of the three lithium salts, $\phi$ for $\mathrm{LiBr}$ was experimentally measured to the highest concentration. Again we notice that this value is close to the HD of $\mathrm{Li}^{+}$in ethanol, $8.87 \AA$ (see Table 5), which is worth of note.

The results of the fits of $\phi$ for the three lithium salts are displayed in Figure 6.

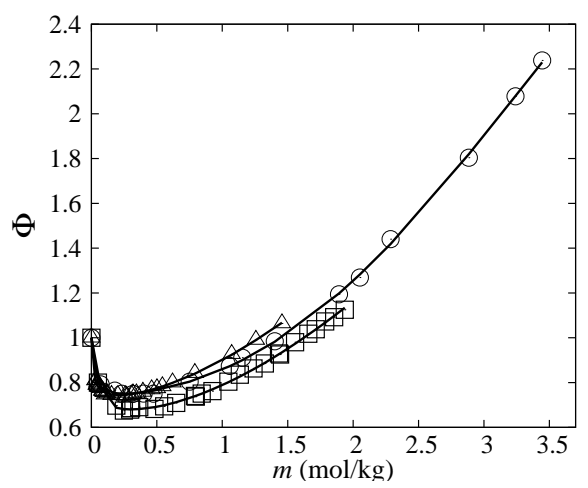

Figure 6: Osmotic coefficient for solutions of lithium salts in ethanol. Symbols: $(\odot) \mathrm{LiCl},(\odot) \mathrm{LiBr}(\triangle) \mathrm{LiClO}$. Solid lines: results from BiMSA model. 

and $\mathrm{LiClO}_{4}$. Again no experimental values are available for the activity coefficients of these salts.

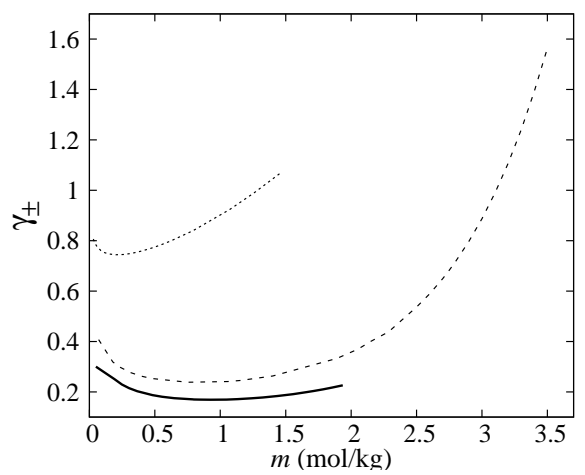

Figure 7: Mean salt activity coefficient computed using the BiMSA model for solutions of LiCl (solid line), LiBr (dashed line) and $\mathrm{LiClO}_{4}$ (dotted line) in ethanol.

The DID for $\mathrm{Na}^{+}$resulted from the adjustment of $\phi$ for the NaI salt. Nevertheless it must be mentioned that the uncertainty on the values of the parameters (in particular on the DID) was not negligible because the maximum concentration $\left(\sim 1.9 \mathrm{~mol} \mathrm{~kg}^{-1}\right)$ was not sufficiently high and because data for only one salt was available.

\subsection{Solutions in 2-propanol}

Here the osmotic coefficients of the three lithium salts are available up to the same moderate concentration of $1.5 \mathrm{~mol} \mathrm{~kg}$ - The DID of $\mathrm{Li}^{+}$was derived from the fits of $\phi$ in the case of $\mathrm{LiBr}$ and $\mathrm{LiClO}_{4}$ which gave $\sigma_{+}^{(0)}=7.07 \AA$ and $7.31 \AA$, respectively (mean value $=7.19 \AA$ ).

As in the case of ethanol, the DID for $\mathrm{Na}^{+}$resulted from the adjustment of $\phi$ for the NaI salt only. It is seen that the fit of $\phi$ in this case gives the lowest accuracy of all fits, exhibiting an AARD of $2 \%$, but this result also seems to be due to a lack of accuracy in the experimental data which do not vary regularly with concentration for $m_{S}<0.6 \mathrm{~mol} \mathrm{~kg}^{-1}$ as seen in Figure 8 .

\subsection{Solutions in acetone}

The DID of $\mathrm{Li}^{+}$ion was imposed by the fit of $\phi$ for $\mathrm{LiClO}_{4}$ for which data exist up to $5.85 \mathrm{~mol} \mathrm{~kg}^{-1}$ while those for $\mathrm{LiBr}$ were measured up to $0.83 \mathrm{~mol} \mathrm{~kg}^{-1}$.

\subsection{Solutions in acetonitrile}

The DID of $\mathrm{Li}^{+}$ion resulted from the fit of osmotic data for $\mathrm{LiClO}_{4}$ which exhibits a low AARD of $0.1 \%$. Moreover the DID value $(7.399 \AA)$ is only less than $10 \%$ larger than the HD value of $6.77 \AA$.

With this result for the DID the data for $\mathrm{LiBr}$ were fitted for $m_{S}>0.1 \mathrm{~mol} \mathrm{~kg}^{-1}$ because they exhibit a large scatter at low concentration. In this fit it was noted that taking the Pauling diameter for the $\mathrm{Br}^{-}$ anion $(3.90 \AA)$ led to a regressed value for $\sigma_{S}^{(1)}$ that was positive, which is not satisfactory (as mentioned 


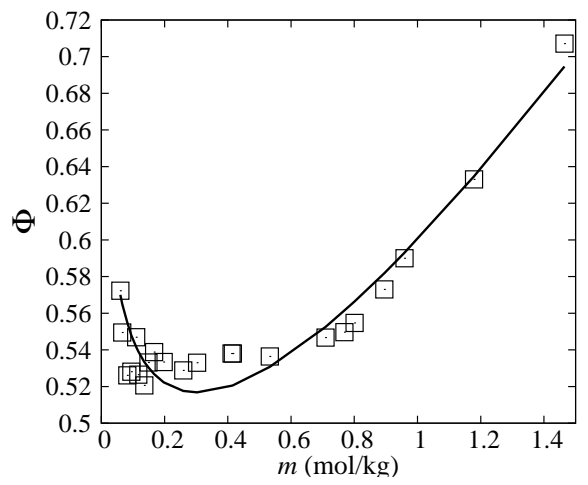

Figure 8: Osmotic coefficient for solutions of NaI in 2-propanol. Symbols: (๑) Experimental data. Solid line: result from BiMSA model.

above $\sigma_{S}^{(1)}$ should be negative so that $\sigma_{+}$decreases with concentration). On the other hand taking the hydrodynamic diameter for the $\mathrm{Br}^{-}$anion in acetonitrile $(4.76 \AA)$ gave a negative value for $\sigma_{S}^{(1)}$.

Here too $\mathrm{NaI}$ was the only salt studied containing the $\mathrm{Na}^{+}$cation. However, the same remarks as in the case of $\mathrm{NaI}$ in ethanol may be made here about the uncertainty on the values of the parameters.

\subsection{Regressed values of association constants}

The adjusted values obtained for $K$ (Table 6) are small for salts in methanol (in the range of 0 to $\sim$ 2.2). They are larger in ethanol ( $K$ between $\sim 3.5$ and 25 ) and still larger in 2-propanol (from $\sim 470$ to $640)$. The higher $K$ value is obtained in the case of $\mathrm{LiBr}$ in acetone $(K \sim 5850)$.

The regressed $K$ values are all lower than those found in the literature $\left(K_{l i t}\right)$ except in the case of $\mathrm{LiBr}$ in acetone. They are much lower in the case of methanol, a few times smaller in the case of ethanol, and of more comparable magnitude in the case of 2-propanol, acetone and acetonitrile. They may even be vanishingly smaller $(K=0)$ as in the case of $\mathrm{NaCl}, \mathrm{KBr}$ and $\mathrm{KI}$ in methanol. A similar trend has already been mentioned elsewhere [99].

Most literature values for $K$ collected in Table 6 were obtained from conductivity experiments. We now briefly discuss the discrepancy observed between the present regressed $K$ values and those estimated in conductivity.

Basically it must be underlined that conductivity measurements are usually carried out at low or very low salt concentrations, typically in the range of $10^{-4}$ to $10^{-1} \mathrm{M}$. This feature may entail non-negligible uncertainties on the $K_{\text {lit }}$ values, in particular if they are not very high [99] (as it would be also the case with a thermodynamic model). Moreover different equations may be used to assess the parameters involved in conductivity experiments. These equations may differ in the ingredients employed to describe the effect of deviations from ideality. It must be noted that the latter are more complicated to calculate than those involved in a thermodynamic model at equilibrium because they require not only some static features regarding the ions (such as their sizes and charges) but also some dynamic characteristics of the ions (their 
diffusion coefficients) and also of the solvent (its viscosity).

For these reasons it has been pointed out that the estimation of $K$ values smaller than $\sim 12 \mathrm{M}^{-1}$ from conductivity experiments depends on the equation used for their determination and are at the lower end of Table 6 are all greater than this limit of $12 \mathrm{M}^{-1}$ but many are not that far from this value (the smallest one is $\left.17.3 \mathrm{M}^{-1}\right)$. Therefore the uncertainty on these $K_{l i t}$ data might be appreciable in the case of solutions in methanol for which they are mostly in the range of 17 to $24 \mathrm{M}^{-1}$. However it is unlikely that these values could be reconciled with the regressed $K$ values displayed in Table 6 , which are much smaller, of the order of unity.

Another, maybe more relevant, remark is that different types of ion-pairing may dominate in solution depending on the concentration at which the experiment is carried out [99]. So it has been observed experimentally using dielectric relaxation spectroscopy that association of $\mathrm{LiClO}_{4}$ in acetonitrile seems to shift from preferential solvent-separated pairs at low concentration to contact ion pairs (CIP's) in concentrated solutions [100]. Therefore different types of association prevailing at low vs. high concentration are likely to lead to different association constants. This might be the case in this work. However, to be confirmed, this point would require a careful experimental study of the systems approached in this work, by using suitable techniques as in ref. [100].

It is also worth mentioning that a description of conductivity experiments in concentrated solutions leads to association constants values that are significantly smaller than with a 'classic' model used for dilute solutions [99].

\subsection{MSA cation diameter vs. hydrodynamic diameter}

The values of the infinite dilution cation diameters in the case of aqueous solutions (Table 5) together with those in organic solutions (Table 3) are presented in Figure 9. In this figure the MSA diameters $\sigma_{+}^{(0)}$ are plotted against the Stokes diameters $\sigma_{h y d}$. This plot suggests a correlation between the regressed MSA diameter, $\sigma_{+}^{(0)}$, and the HD, $\sigma_{\text {hyd }}$. A fit of the points of Figure gives, $\sigma_{+}^{(0)}=(1.008 \pm 0.026) \times \sigma_{\text {hyd }}$.

This result means that the Stokes diameter may provide a good estimate of the MSA diameter for use in the MSA or BiMSA model. This is what has been done in this work in the case of $\mathrm{Na}^{+}$in ethanol and acetonitrile.

\section{Conclusion}

A great deal of work has been accomplished in the literature about deviations from ideality in organic electrolyte solutions, mainly by Barthel and collaborators who have greatly contributed to both the experimental and modeling sides. Available experimental data showed that most salts are associated. Models need to account for ion-pairing.

In the present study, the BiMSA model has been applied to describe the osmotic coefficients for solutions of 1-1 salts in organic solvents. By and large, descriptions have been obtained with good accuracy up to the 


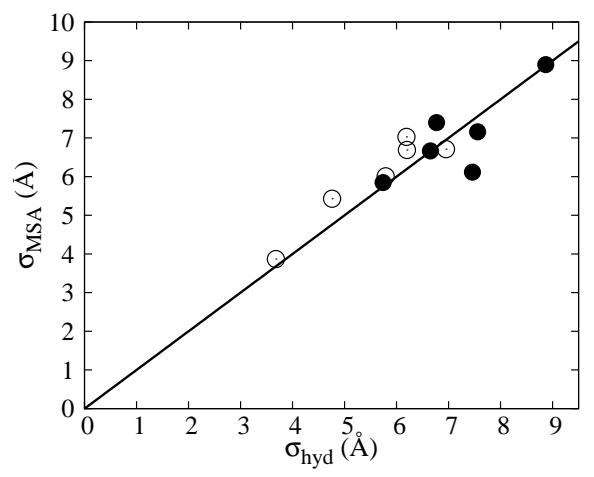

Figure 9: Optimum MSA cation diameters $\sigma_{+}^{(0)}$ obtained in ref. [35] for aqueous solutions $(\odot)$, and in this work for organic solutions $(\bullet)$, against the Stokes diameters, $\sigma_{h y d}$. The straight line represents the case $\sigma_{+}^{(0)}=\sigma_{h y d}$.

maximum concentrations to which data are available. The model is developed in terms of parameters that have a physical meaning, such as ion sizes, solution permittivity and association constants.

On the experimental side it would be interesting to acquire more data about the thermodynamic propdoes not seem to have received much attention. A few solvents may have dielectric constants greater than that of water. Such solvents include formamide, n-methylformamide or n-methylacetamide, for which $\varepsilon_{\text {org }}$ ranges from $\sim 109$ to $\sim 187$ [65].

Moreover, it would be interesting to extend the use of spectroscopic and relaxation techniques, as was done in refs. [65, 100], to a greater number of salts and solvents. This may provide more insight into the nature of ion-pairs that are formed in these solutions, possibly as a function of salt concentration. Depending on the type of association (solvent-separated ion pairs, contact ions pairs, triple ions, etc.) it could be attempted to build a suitable model to describe the structure and the thermodynamic properties of the electrolyte up to high concentrations. Certainly the MSA is a convenient framework to elaborate such models, as exemplified by a few past studies based on the AMSA or BiMSA theories $[11,101,102]$.

Lastly, the nature of the solvation of anions in organic solvents does not seem to be quite clear presently. This phenomenon may also deserve further experimental examination in the future.

\section{References}

[1] Y. Peng, Z. Zhu, R. D. Braatz, A. S. Myerson, Gypsum crystallization during phosphoric acid production: Modeling and experiments using the mixed-solvent-electrolyte thermodynamic model, Ind. Eng. Chem. Res. 54 (2015) 7914-7924. doi:10.1021/acs.iecr.5b01763.

[2] D. Meranda, W. F. Furter, Vapor-liquid equilibrium in alcohol-water systems containing dissolved halide salts and salt mixtures, AIChE J. 18 (1972) 111-116. doi:10.1002/aic.690180120. 
[3] K. Xu, Nonaqueous liquid electrolytes for lithium-based rechargeable batteries, Chem. Rev. 104 (2004) 4303-4418. doi:10.1021/cr030203g.

[4] H. Gores, J. Barthel, Nonaqueous electrolyte solutions: New materials for devices and processes based on recent applied research, Pure Applied Chem. 67 (1995) 919-930.

[5] O. F. Tower, A. F. O. Germann, Vapor pressures of certain alcoholic solutions., J. Am. Chem. Soc. 36 (12) (1914) 2449-2456. doi:10.1021/ja02189a003.

[6] A. M. Hayward, E. P. Perman, Vapour pressure and heat of dilution.- Part VII. Vapour pressures of aqueous solutions of sodium hydroxide and of alcoholic solutions of calcium chloride, Trans. Faraday Soc. 27 (1931) 59-69. doi:10.1039/TF9312700059.

[7] R. Mar, R. Carling, The calcium chloride-ethanol system, Thermochim. Acta 45 (1981) 213-217.

[8] J. Barthel, R. Neueder, W. Kunz, Osmotic coefficients of non-aqueous electrolyte solutions at thermodynamic and McMillan-Mayer level, Pure Applied Chem. 65 (1993) 889-894.

[9] J. Barthel, H. Krienke, R. Neueder, M. Holovko, The role of ion-aggregate formation in the calculation of physical properties of electrolyte solutions, Fluid Phase Equilib. 194 (2002) 107-122.

[10] W. R. Fawcett, A. C. Tikanen, Application of the mean spherical approximation to the estimation of electrolyte activity coefficients in methanol solutions, J. Mol. Liq. 73 (1997) 373-384.

[11] J. Barthel, H. Krienke, M. Holovko, V. Kapko, I. Protsykevich, The application of the associative mean spherical approximation in the theory of nonaqueous electrolyte solutions, Condens. Matter Phys. 3 (2000) 657-674.

[12] W. G. McMillan, J. E. Mayer, The statistical thermodynamics of multicomponent systems, J. Chem. Phys. 13 (1945) 276-305.

[13] H. Friedman, Lewis-Randall to McMillan-Mayer conversion for the thermodynamic excess functions of solutions. Part I. Partial free energy coefficients, J. Solution Chem. 1 (5) (1972) 387-412.

[14] B. Pailthorpe, D. Mitchell, B. Ninham, Ion-solvent interactions and the activity coefficients of real electrolyte solutions, J. Chem. Soc. Faraday Trans. 280 (1984) 115-139.

[15] J.-P. Simonin, Study of experimental-to-McMillan-Mayer conversion of thermodynamic excess functions, J. Chem. Soc. Faraday Trans. 92 (1996) 3519-3523.

[16] D. Stigter, Interactions in aqueous solutions. II. Osmotic pressure and osmotic coefficient of sucrose and glucose solutions, J. Phys. Chem. 64 (1960) 118-124. 
[17] B. Behzadi, B. Patel, A. Galindo, C. Ghotbi, Modeling electrolyte solutions with the saft-vr equation using yukawa potentials and the mean-spherical approximation, Fluid Phase Equilib. 236 (2005) 241 - 255. doi:https://doi.org/10.1016/j.fluid.2005.07.019.

[18] C. Held, A. Prinz, V. Wallmeyer, G. Sadowski, Measuring and modeling alcohol/salt systems, Chemical engineering science 68 (2012) 328-339.

[19] J. Barthel, H. Krienke, W. Kunz, Physical chemistry of electrolyte solutions: modern aspects, Vol. 5 of Topics in physical chemistry, Springer Science \& Business Media, Steinkopff, Darmstadt, 1998.

[20] J. Barthel, R. Neueder, G. Lauermann, Vapor pressures of non-aqueous electrolyte solutions. Part 1. Alkali metal salts in methanol, J. Solution Chem. 14 (1985) 621-633.

[21] J. Barthel, G. Lauermann, Vapor pressure measurements on non-aqueous electrolyte solutions. Part 3: Solutions of sodium lodide in ethanol, 2-propanol, and acetonitrile, J. Solution Chem. 15 (1986) 869-877.

[22] J. Barthel, R. Neueder, H. Poepke, H. Wittmann, Osmotic and activity coefficients of nonaqueous electrolyte solutions. 1. lithium perchlorate in the protic solvents methanol, ethanol, and 2-propanol, J. Solution Chem. 27 (1998) 1055-1066.

[23] J. Barthel, R. Neueder, H. Poepke, H. Wittmann, Osmotic coefficients and activity coefficients of nonaqueous electrolyte solutions. Part 4. Lithium bromide, tetrabutylammonium bromide, and tetrabutylammonium perchlorate in acetone, J. Solution Chem. 28 (1999) 1277-1287.

[24] K. Nasirzadeh, R. Neueder, W. Kunz, Vapor pressures, osmotic and activity coefficients of electrolytes in protic solvents at different temperatures. 2. Lithium bromide in ethanol, J. Solution Chem. 33 (2004) 1429-1446.

[25] J. Barthel, G. Lauermann, Vapor pressure measurements on non-aqueous electrolyte solutions. Part 3: Solutions of sodium lodide in ethanol, 2-propanol, and acetonitrile, J. Solution Chem. 15 (1986) 869-877. doi:10.1007/BF00646093.

[26] H. Krienke, J. Barthel, M. Holovko, I. Protsykevich, Y. Kalyushnyi, Osmotic and activity coefficients of strongly associated electrolytes over large concentration ranges from chemical model calculations, J. Mol. Liq. 87 (2000) 191-216.

[27] L. Blum, Simple electrolytes in the mean spherical approximation, in: H. Eyring, D. Henderson (Eds.), Theoretical Chemistry, Advances and Perspectives, Vol. 5, Academic Press: New York, 1980, pp. 1-66.

[28] M. Wertheim, Fluids with highly directional attractive forces. I. Statistical thermodynamics, J. Stat. Phys. 35 (1984) 19-34. 
[29] M. Wertheim, Fluids with highly directional attractive forces. II. Thermodynamic perturbation theory and integral equations, J. Stat. Phys. 35 (1984) 35-47.

[30] L. Blum, O. Bernard, The general solution of the binding mean spherical approximation for pairing ions, J. Stat. Phys. 79 (1995) 569-583.

[31] O. Bernard, L. Blum, Binding mean spherical approximation for pairing ions: an exponential approximation and thermodynamics, J. Chem. Phys. 104 (1996) 4746-4754.

[32] J.-P. Simonin, O. Bernard, L. Blum, Real ionic solutions in the mean spherical approximation. 3. Osmotic and activity coefficients for associating electrolytes in the primitive model, J. Phys. Chem. B 102 (1998) 4411-4417.

[33] J.-P. Simonin, O. Bernard, L. Blum, Ionic solutions in the binding mean spherical approximation: thermodynamic properties of mixtures of associating electrolytes, J. Phys. Chem. B 103 (1999) 699704.

[34] A. Ruas, P. Moisy, J.-P. Simonin, O. Bernard, J.-F. Dufrêche, P. Turq, Lanthanide salts solutions: Representation of osmotic coefficients within the binding mean spherical approximation, J. Phys. Chem. B 109 (2005) 5243-5248.

[35] J.-P. Simonin, Real ionic solutions in the mean spherical approximation. 2. Pure strong electrolytes up to very high concentrations, and mixtures, in the primitive model, J. Phys. Chem. B 101 (1997) 4313-4320.

[36] W. R. Fawcett, Thermodynamic parameters for the solvation of monatomic ions in water, J. Phys. Chem. B 103 (1999) 11181-11185.

[37] S. Cummings, J. Enderby, G. W. Neilson, J. Newsome, R. Howe, W. Howells, A. Soper, Chloride ions in aqueous solutions, Nature 287 (1980) 714-716.

[38] G. Neilson, J. Enderby, The structure around nitrate ions in concentrated aqueous solutions, J. Phys. C 15 (1982) 2347-2352.

[39] P. Skabichevskii, Osmotic coefficients of lithium chloride and bromide solutions in methanol, Russ. J. Phys. Chem. 43 (1969) 1432-1433.

[40] Y. G. Vlaslov, P. Antonow, Activity of methanol and activity coefficients of salts in sodium choridemethanol and sodium bromide-methanol solutions at 25c, Russ. J. Phys. Chem. 47 (1973) 1278-1279.

[41] O. Bonner, The colligative properties of certain electrolytes and non-electrolytes in methanol, J. Solution Chem. 16 (1987) 307-314. 
[42] P. Tomasula, G. J. Czerwienski, D. Tassios, Vapor pressures and osmotic coefficients: electrolyte solutions of methanol, Fluid Phase Equilib. 38 (1987) 129-153.

[43] M. T. Zafarani-Moattar, K. Nasirzade, Osmotic coefficient of methanol $+\mathrm{LiCl},+\mathrm{LiBr}$, and + $\mathrm{LiCH}_{3} \mathrm{COO}$ at $25^{\circ} \mathrm{C}$, J. Chem. Eng. Data 43 (1998) 215-219. doi:10.1021/je970193e.

[44] K. Nasirzadeh, R. Neueder, Measurement and correlation of osmotic coefficients and evaluation of vapor pressure for electrolyte solutions of $\mathrm{LiClO}_{4}$ and $\mathrm{LiNO}_{3}$ in methanol at $25^{\circ} \mathrm{C}$, J. Mol. Liq. 113 (2004) 13-20.

[45] K. Nasirzadeh, N. Papaiconomou, R. Neueder, W. Kunz, Vapor pressures, osmotic and activity coefficients of electrolytes in protic solvents at different temperatures. 1. Lithium bromide in methanol, J. Solution Chem. 33 (2004) 227-245.

[46] M. T. Zafarani-Moattar, J. Jahanbin-Sardroodi, Isopiestic determination of osmotic coefficients and evaluation of vapor pressures for electrolyte solutions of some lithium salts in ethanol, Fluid Phase Equilib. 166 (1999) 207-223.

[47] M. T. Zafarani-Moattar, M. Aria, Isopiestic determination of osmotic and activity coefficients for solutions of $\mathrm{LiCl}, \mathrm{LiBr}$, and $\mathrm{LiNO}_{3}$ in 2-propanol at 25 C, J. Solution Chem. 30 (2001) 351-363.

[48] M. T. Zafarani-Moattar, J. Jahanbin-Sardroodi, Measurement and correlation of osmotic coefficients and evaluation of vapor pressures for solutions of $\mathrm{CaCl}_{2}$ and $\mathrm{Ca}\left(\mathrm{NO}_{3}\right)_{2}$ in ethanol at $298 \mathrm{~K}$, Fluid Phase Equilib. 172 (2000) 221-235.

[49] M. Zafarani-Moattar, J. J. Sardroodi, K. Nasirzadeh, Isopiestic determination of osmotic coefficients and evaluation of vapor pressures for solutions of calcium chloride and calcium nitrate in methanol at 298.15 K, Fluid Phase Equilib. 200 (2002) 173-185.

[50] J. Barthel, G. Lauermann, R. Neueder, Vapor pressure measurements on non-aqueous electrolyte solutions. Part 2. Tetraalkylammonium salts in methanol. activity coefficients of various 1-1 electrolytes at high concentrations, J. Solution Chem. 15 (10) (1986) 851-867. doi:10.1007/BF00646092.

[51] O. Bonner, Š. Paljk, C. Klofutar, Association studies of tetramethylguanidinium perchlorate and tetramethylguanidinium chloride in ethanol solutions at 25 C, J. Solution Chem. 20 (1991) 539-550.

[52] K. E. N'Tsoukpoe, H. U. Rammelberg, A. F. Lele, K. Korhammer, B. A. Watts, T. Schmidt, W. K. Ruck, A review on the use of calcium chloride in applied thermal engineering, Appl. Therm. Eng. 75 (2015) 513-531.

[53] K. Korhammer, C. Apel, T. Osterland, W. K. Ruck, Reaction of calcium chloride and magnesium chloride and their mixed salts with ethanol for thermal energy storage, Energy Procedia 91 (2016) $161-171$. 
[54] J. Barthel, R. Neueder, H. Poepke, H. Wittmann, Osmotic coefficients and activity coefficients of nonaqueous electrolyte solutions. Part 2. Lithium perchlorate in the aprotic solvents acetone, acetonitrile, dimethoxyethane, and dimethylcarbonate, J. Solution Chem. 28 (1999) 489-503.

[55] W. Kunz, J. Barthel, L. Klein, T. Cartailler, P. Turq, B. Reindl, Lithium bromide in acetonitrile: thermodynamics, theory, and simulation, J. Solution Chem. 20 (1991) 875-891.

[56] I. Wichterle, J. Linek, Z. Wagner, H. V. Kehiaian, Vapor-liquid equilibrium in mixtures and solutions bibliographic database. EVLM'2003, 5th Edition, Electronic Data (ELDATA), Paris, France, 2003, electronic edition, 1888-2003.

[57] L. Blum, J. Høye, Mean spherical model for asymmetric electrolytes. 2. Thermodynamic properties and the pair correlation function, J. Phys. Chem. 81 (1977) 1311-1316.

[58] B. Maribo-Mogensen, G. M. Kontogeorgis, K. Thomsen, Comparison of the debye-huückel and the mean spherical approximation theories for electrolyte solutions, Ind. Eng. Chem. Res. 51 (2012) 53535363.

[59] M. Wertheim, Fluids of dimerizing hard spheres, and fluid mixtures of hard spheres and dispheres, J. Chem. Phys. 85 (5) (1986) 2929-2936.

[60] J.-P. Simonin, L. Blum, P. Turq, Real ionic solutions in the mean spherical approximation. 1. Simple salts in the primitive model, J. Phys. Chem. 100 (1996) 7704-7709.

[61] J.-P. Simonin, O. Bernard, L. Blum, Description of the thermodynamic properties of aqueous ionic solutions within the mean spherical approximation, Oil Gas Sci. Technol. 63 (2008) 321-327.

[62] W. R. Fawcett, A. C. Tikanen, Role of solvent permittivity in estimation of electrolyte activity coefficients on the basis of the mean spherical approximation, J. Phys. Chem. 100 (1996) 4251-4255.

[63] L. Blum, F. Vericat, W. R. Fawcett, On the mean spherical approximation for hard ions and dipoles, J. Chem. Phys. 96 (1992) 3039-3044.

[64] L. Blum, F. Vericat, W. R. Fawcett, Erratum: On the mean spherical approximation for hard ions and dipoles [J. Chem. Phys. 96, 3039 (1992)], J. Chem. Phys. 101 (1994) 10197-10197. doi:10.1063/1.468516.

[65] J. Barthel, H.-J. Gores, G. Schmeer, R. Wachter, Non-aqueous electrolyte solutions in chemistry and modern technology, in: Physical and Inorganic Chemistry, Vol. 111 of Topics in current chemistry, Springer Berlin Heidelberg, Berlin, Heidelberg, 1983, pp. 33-144. doi :10.1007/3-540-12065-3_2.

[66] R. D. Nelson Jr, D. R. Lide Jr, A. A. Maryott, Selected values of electric dipole moments for molecules in the gas phase, Tech. rep., National Standard Reference Data System, NBS (1967). 
[67] C. Gray, K. Gubbins, Theory of molecular fluids, Vol. 1, Clarendon Press, Oxford, 1984.

[68] O. Söhnel, P. Novotnỳ, Densities of aqueous solutions of inorganic substances, Vol. 22, Elsevier Publishing Company, Amsterdam, 1985.

[69] R. Larson, H. Hunt, Molecular forces and solvent power, J. Phys. Chem. 43 (1939) 417-423.

[70] W. C. Vosburgh, L. Connell, J. Butler, The electrostriction produced by salts in some aliphatic alcohols, J. Chem. Soc. (1933) 933-942.

[71] M. T. Zafarani-Moattar, H. Shekaari, Density and speed of sound of lithium bromide with organic solvents: Measurement and correlation, J. Chem. Thermodyn. 39 (2007) 1649-1660.

[72] A. J. Pasztor, C. M. Criss, Apparent molal volumes and heat capacities of some 1:1 electrolytes in anhydrous methanol at $25^{\circ} \mathrm{C}$, J. Solution Chem. 7 (1978) 27-44.

[73] L. Werblan, A. Rotowska, S. Minc, Viscosity of water-methanol solutions of $\mathrm{LiClO}_{4}, \mathrm{NaClO}_{4}$ and $\mathrm{NaCl}$, Electrochim. Acta 16 (1971) 41-59.

[74] R. R. Pawar, C. S. Aher, J. D. Pagar, S. L. Nikam, M. Hasan, Solubility, density and solution thermodynamics of $\mathrm{NaI}$ in different pure solvents and binary mixtures, J. Chem. Eng. Data 57 (2012) $3563-3572$.

[75] W. Cox, J. Wolfenden, The viscosity of strong electrolytes measured by a differential method, Proc. Roy. Soc. A 145 (1934) 475-488.

[76] R. Tomkins, E. Andalaft, G. Janz, Conductance, density, and viscosity of nai in anhydrous acetonitrile at $25^{\circ}$ c, Trans. Faraday Soc. 65 (1969) 1906-1911.

[77] R. Robinson, R. Stokes, Electrolyte Solutions, Butterworths, London, 1968.

[78] R. Jervis, D. Muir, J. Butler, A. Gordon, The conductance at $25^{\circ}$ of lithium chloride, sodium and potassium bromides and potassium iodide in methanol, and of lithium chloride, sodium bromide and potassium iodide in water, J. Am. Chem. Soc. 75 (1953) 2855-2858.

[79] J. Barthel, M. Krell, L. Iberl, F. Feuerlein, Conductance of 1-1 electrolytes in methanol solutions from -45 to $+23^{\circ} \mathrm{C}$, J. Electroanal. Chem. Interf. Electrochem. 214 (1986) 485-505.

[80] J. Graham, G. Kell, A. Gordon, Equivalent and ionic conductances for lithium, sodium and potassium chlorides in anhydrous ethanol at 25, J. Am. Chem. Soc. 79 (1957) 2352-2355.

[81] N. Schmelzer, J. Einfeldt, M. Grigo, Measurements of the electrolyte conductivity of alkali-metal perchlorates and $\mathrm{LiNO}_{3}$ in acetone at 25 C, J. Chem. Soc. Faraday Trans. 184 (1988) 931-939. 
[82] D. F. Evans, J. Thomas, J. A. Nadas, S. M. A. Matesich, Conductance of electrolytes in acetone and in 1-propanol-acetone mixtures at 25, J. Phys. Chem. 75 (1971) 1714-1722.

[83] H. P. Hopkins, D. Jahagirdar, A. B. Norman, Conductance studies on lithium salt-acetonitrile solutions at $25^{\circ}$ C, J. Solution Chem. 8 (1979) 147-155.

[84] H. P. Hopkins Jr, A. B. Norman, Conductance and infrared studies on acetonitrile solutions containing crown ethers and alkali metal salts, J. Phys. Chem. 84 (1980) 309-314.

[85] J. Coetzee, G. Cunningham, Evaluation of single ion conductivities in acetonitrile, nitromethane, and nitrobenzene using tetraisoamylammonium tetraisoamylboride as reference electrolyte, J. Am. Chem. Soc. 87 (1965) 2529-2534.

[86] J. E. Huheey, E. A. Keiter, R. L. Keiter, O. K. Medhi, Inorganic chemistry: principles of structure and reactivity, Pearson Education India, 2006.

[87] H. Jenkins, K. Thakur, Reappraisal of thermochemical radii for complex ions, J. Chem. Educ. 56 (9) (1979) 576.

[88] B. Conway, The evaluation and use of properties of individual ions in slution, J. Solution Chem. 7 (1978) $721-770$.

[89] Z. Chen, M. Hojo, Relationship between triple ion formation constants and the salt concentration of the minimum in the conductometric curves in low-permittivity solvents, J. Phys. Chem. B 101 (1997) 10896-10902.

[90] P. K. Muhuri, B. Das, D. K. Hazra, Ionic association of some lithium salts in 1,2-dimethoxyethane. A Raman spectroscopic and conductivity study, J. Phys. Chem. B 101 (1997) 3329-3332.

[91] M. Delsignore, H. Farber, S. Petrucci, Ionic conductivity and microwave dielectric relaxation of lithium hexafluoroarsenate $\left(\mathrm{LiAsF}_{6}\right)$ and lithium perchlorate $\left(\mathrm{LiClO}_{4}\right)$ in dimethyl carbonate, J. Phys. Chem. 89 (1985) 4968-4973.

[92] J. Barthel, R. Neueder, Conductivities, transference numbers, limiting ionic conductivities (of methanol solutions), in: Electrolyte Data Collection, Vol. XII, part 1 of DECHEMA Chemistry Data Series, DECHEMA, Frankfurt am Main, 1992.

[93] E. Bixon, R. Guerry, D. Tassios, Salt effect on the vapor pressure of pure solvents: Methanol with seven salts at $24.9^{\circ} \mathrm{C}$, J. Chem. Eng. Data 24 (1979) 9-11. doi:10.1021/je60080a005.

[94] J. Barthel, R. Neueder, Conductivities, transference numbers, limiting ionic conductivities of ethanol solutions, in: Electrolyte Data Collection, Vol. XII, part 1a of DECHEMA Chemistry Data Series, DECHEMA, Frankfurt am Main, 1993. 
[95] L. G. Savedoff, Conductance of electrolytes in anhydrous acetone, J. Am. Chem. Soc. 88 (1966) 664667.

[96] C. W. Jones, C. M. Cunningham, Electrolytic Conductance of Lithium Bromide in Acetone and Acetone-Bromosuccinic Acid Solutions, Vol. 155 of Adv. Chem., American Chemical Society, 1976, Ch. 14, pp. 244-262. doi:10.1021/ba-1976-0155.ch014.

[97] M. S. K. Niazi, Conductance of electrolytes in dipolar aprotic solvent mixtures. II. Conductance of lithium perchlorate in mixtures of ethyl methyl ketone and acetone with n,n-dimethylformamide at 25드. Bull. Chem. Soc. Jpn. 61 (1988) 2165-2170. doi:10.1246/bcsj.61.2165.

[98] P. G. Glugla, J. H. Byon, C. A. Eckert, Pressure effects on conductivity and ionic association of some monovalent salts in aprotic dipolar solvents, J. Chem. Eng. Data 26 (1981) 80-84.

[99] J. Barthel, H. Graml, R. Neueder, P. Turq, O. Bernard, Electrolyte conductivity from infinite dilution to saturation, Curr. Top. Solution Chem. 1 (1994) 223-239.

[100] J. Barthel, R. Buchner, P.-N. Eberspächer, M. Münsterer, J. Stauber, B. Wurm, Dielectric relaxation spectroscopy of electrolyte solutions. recent developments and prospects, J. Mol. Liq. 78 (1) (1998) 83 - 109. doi:http://dx.doi.org/10.1016/S0167-7322(98)00085-3.

[101] T. Vilariño, O. Bernard, J.-P. Simonin, Ionic solutions in the binding mean spherical approximation. Thermodynamics of associating electrolytes up to very high concentrations, J. Phys. Chem. B 108 (2004) 5763-5770.

[102] S. Hlushak, J. P. Simonin, S. De Sio, O. Bernard, A. Ruas, P. Pochon, S. Jan, P. Moisy, Speciation in aqueous solutions of nitric acid, Dalton Trans. (2013) 2853-2860doi:10.1039/C2DT32256K. 